\title{
Familial Camptodactyly with Taurinuria
}

\author{
N. C. NEVIN*, L. J. HURWITZ, and D. W. NEILL \\ From Royal Victoria Hospital, Belfast
}

Camptodactyly is a permanent flexion contracture of the fingers at the proximal interphalangeal joints which may be familial or sporadic (Landouzy, 1906; Gates, 1946). In practically all instances it affects the little finger. In addition the ring, middle, and index fingers may be involved. It is usually bilateral. Although there is no limitation to further flexion of the fingers, complete extension is impossible. The flexed fingers which are slender and tapering have a sluggish peripheral circulation. The condition has been described also as congenital contracture of the fingers (Adams, I891; Neuhof and Oppenheimer, 1914), campylodactyly (Oldfield, 1956), palmar clinodactyly, and congenital Dupuytren's contracture (Currarino and Waldman, I964). Several authors have referred to the anomaly as streblomicrodactyly (Schmidt, I92 I ; Hefner, 1924, 1929, I94I; Ritterskamp, 1936; Moore and Messina, 1936; Ashley, 1947): this, however, applies to the condition in the little fingers, but where one or more fingers are affected camptodactyly is a more appropriate term (Stoddard, 1939; Dutta, 1965).

Parish, Horn, and Thompson (1963) described a family where ro females in 3 generations had an unusual flexion deformity of the fingers and thumb (which they termed streblodactyly) and aminoaciduria. Two other unaffected females but no males tested in the family also had aminoaciduria.

This paper describes 4 unrelated families (Fig. I) in which certain members had a permanent flexion contracture of the fingers also associated with an aminoaciduria.

\section{Case Reports}

Family 1. In 1958, the propositus (III.10), a I6-year-old girl, was referred to the hospital for investigation of a flexion contracture of both hands. This began at the age of 7 with flexion of the left little finger and was followed rapidly by a similar deformity on the right. Since the age of 14 all the fingers have been involved.

Received June ro, 1966.

* Present address: Medical Research Council Clinical Genetics Research Unit, Institute of Child Health, London W.C.I.
The deformity did not interfere with the performance of skilled movements, and though there was no difficulty in making a fist, complete extension of the fingers was impossible.

At her last attendance in 1965 , the following features were present. The deformity (Fig. 2 and 3 ) consisted of marked flexion at the proximal interphalangeal joints of the little fingers ( 90 degrees on the right and 45 degrees on the left). There was a flexion of 50 degrees of the ring finger, 35 degrees of the middle, and 20 degrees of the index fingers of the left hand. On the right hand there was a flexion deformity at the proximal interphalangeal joint of the ring finger of 20 degrees and of I 5 degrees of the middle and index fingers. The thumbs were also slightly flexed. The peripheral circulation of the fingers was poor. There was also a minor degree of hammer-toe deformity.

Haemoglobin, total and differential white cell count, erythrocyte sedimentation rate, and Wassermann and Kahn reactions were normal. Radiographs of the cervical spine showed no bone or joint abnormality. Nerve conduction in the left median, ulnar, and peroneal nerves was within normal limits.

Family History. The patient's father (II.9) had a slight flexion contracture of the hands mainly affecting the little and ring fingers. $\mathrm{He}$ also had hammer-toes. There was no abnormality of either the hands or feet in the mother (II.IO), a paternal aunt (II.7), and a twin brother (III.II). The youngest brother (III.I2), however, had a flexion contracture of both little fingers (streblomicrodactyly). The remainder of the family was not available for examination.

The bones of the hands were measured on radiographs. In the propositus and her relatives the index of relative slenderness and the metacarpal index (Sinclair, Kitchin, and Turner, 1960) were normal. The length and width of each metacarpal and phalanx were also within the normal range.

Urinary chromatograms were carried out using the 'rack tank' technique (Datta, Dent, and Harris, 1950). The urinary chromatogram in the propositus (III.IO), her brothers (III.II) and (III.I2), and her father (II.9) each showed an abnormally large spot in the position usually occupied by taurine. Specimens of the propositus' urine and plasma were submitted to Dr Cusworth of University College Hospital, London, for further identification. The plasma amino acids were normal (taurine $0.75 \mathrm{mg} . / 100 \mathrm{ml}$.). Over a fasting 3-hour 

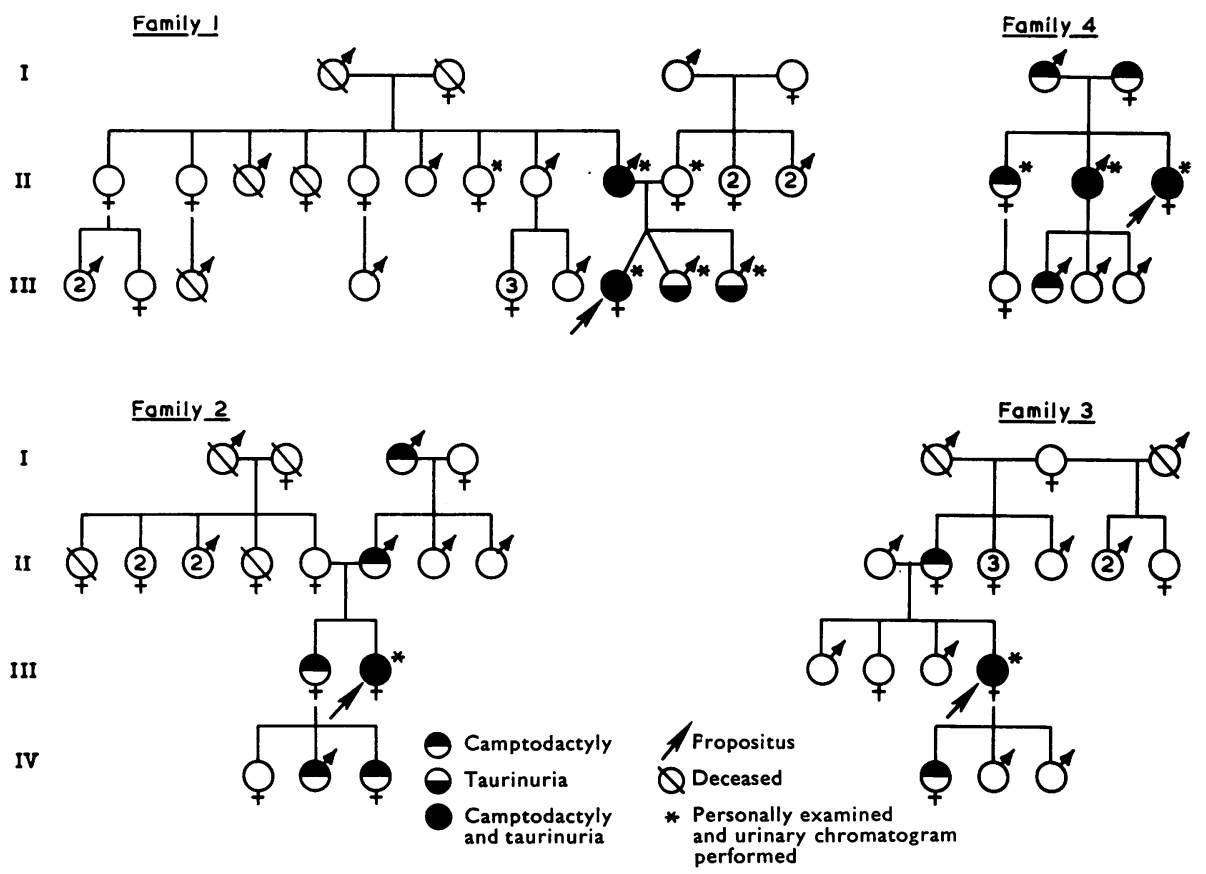

FrG. 1. Pedigrees of families I, 2, 3, and 4 .

period urinary taurine was $103 \mu \mathrm{g} . / \mathrm{min}$., giving a renal clearance for taurine of $13.8 \mathrm{ml}$. $/ \mathrm{min}$. In the mother (II.IO) and the paternal aunt (II.7) the urinary amino acid pattern was normal.

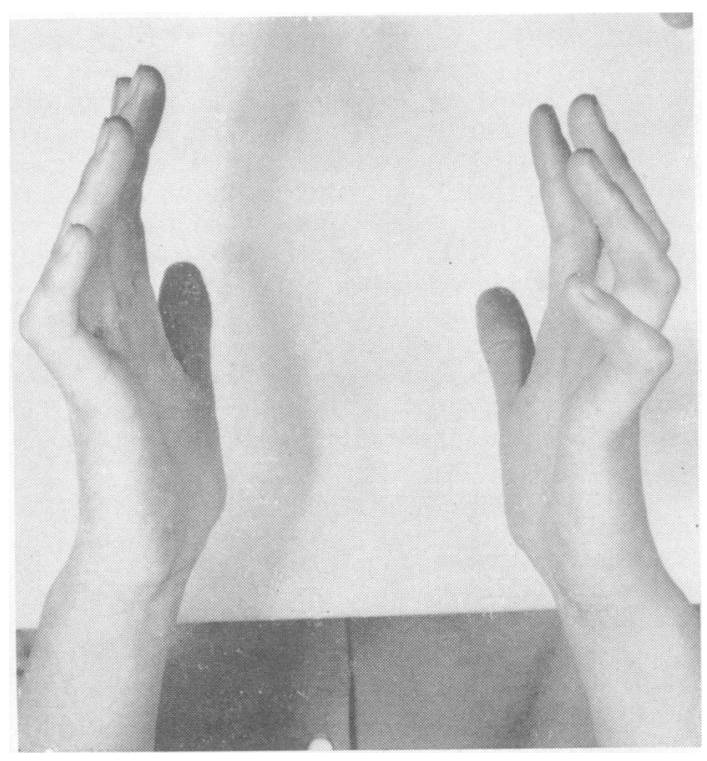

FIG. 2. Hands of propositus (III.ro, family I), lateral view.
Family 2. The propositus (III.2), a 42-year-old spinster, was referred to hospital for investigation of dizziness and headache. It was noted that she had an deformity of both hands similar to that of the propositus in family $\mathrm{I}$. The little and ring fingers were flexed at the proximal interphalangeal joints but the middle and $\vec{b}$ index fingers showed no abnormality. The length an $B$ width of the phalanges and the matacarpals were within? normal limits. The urinary chromatogram revealed. an abnormally large spot in the position of taurine.

Family History. The propositus was anxious tha other members of the family should not be examined but described a similar flexion contracture of the fingers in other relatives (I.3, II.8, III.I, IV.2, and IV.3).

Family 3. The propositus (III.4), a 35-year-old married woman, was admitted to hospital for a hysterectomy. In the course of examination it was noted thato she had a flexion contracture of both hands, involving the little, ring, and middle fingers. Bone measurements were normal. The urinary chromatogram showed an excessive excretion of taurine.

Family History. The propositus refused permission to investigate other relatives but described similar deformities in her daugh:er (IV.I) and her mother (II.2)

Family 4. The propositus (II.3), a 34-year-old ${ }^{5}$ woman, was admitted following a severe motor accident It was noted that she had a flexion deformity of the fingers of both hands characteristic of camptodactyly 


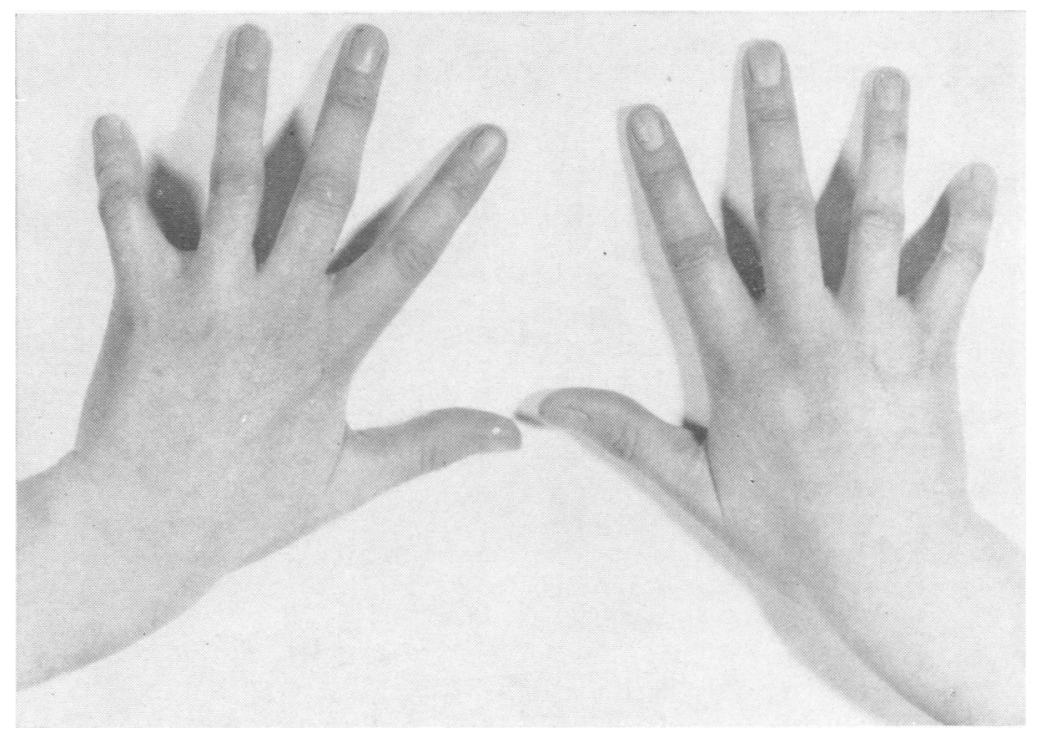

FIG. 3. Hands of propositus (III.Io, family I), dorsal view.

An abnormally large spot in the position of taurine was present in the urinary chromatogram. Bone measurements were normal.

Family History. The patient described similar deformities in her parents (I.I and I.2), her brother (II.2), her sister (II.I), and in a nephew (III.2). Urinary chromatograms of her two sibs showed an abnormal pattern in the brother (II.2).

\section{Discussion}

Flexion deformities of the hands are not uncommon. They have been described in conditions such as arthrogryposis multiplex congenita, Leri's pleonosteosis, trisomy I7-18, lobster claw hand, syndactyly, polydactyly, brachydactyly, and Dupuytren's contracture, and have also been observed secondary to neurological disorders and following infection, trauma, or burns. The term camptodactyly is used for a clinical entity characterized by a permanent flexion contracture of the fingers at the proximal interphalangeal joints (Gates, 1946; Stoddard, 1939). Affected subjects in the 4 families presented an appearance similar to that seen in previous descriptions of camptodactyly. Although there was a superficial resemblance, the deformity differed from that in the family described by Parish et al. (1963). In the present cases flexion of the thumb was a minor feature and measurements of the metacarpals and phalanges were within the normal range. They did, however, resemble the cases of Parish and his associates in having an abnormal urinary chromatogram. With twodimensional chromatography an abnormally large spot was detected in the position usually occupied by taurine. Identification of the amino acids in the plasma and urine suggested that the excessive excretion of taurine was of renal origin. The pattern was present in 6 of the 7 affected subjects and in one of the 3 normal relatives examined. In 3 unrelated patients with streblomicrodactyly urinary chromatograms were normal (Table I). The patient (III.I2) in family $I$ who had streblomicrodactyly had an increased excretion of taurine.

Taurine is not an amino acid but a sulphonated amine which arises as the end-product of metabolism of sulphur-containing amino acids, par-

\section{TABLE I}

URINARY AMINO ACID CHROMATOGRAMS IN PATIENTS WITH CAMPTODACTYLY AND RELATIVES AND IN UNRELATED PERSONS WITH STREBLOMICRODACTYLY

\begin{tabular}{lccc}
\hline & Urinary Chromatograms & No. \\
\hline $\begin{array}{c}\text { Examined } \\
\text { Patients with } \\
\text { camptodactyly }\end{array}$ & 7 & $\begin{array}{c}\text { No. With } \\
\text { Excess Taurine }\end{array}$ & $\begin{array}{c}\text { No. } \\
\text { Normal }\end{array}$ \\
$\begin{array}{c}\text { Normal subjects in } \\
\text { families }\end{array}$ & 3 & I & 2 \\
\hline $\begin{array}{c}\text { Unrelated patients with } \\
\text { streblomicrodactyly }\end{array}$ & 3 & 0 & 3 \\
\hline
\end{tabular}


ticularly cysteine and cystine. This amino-sulphonic acid taurine occurs as a normal constituent of urine. Its urinary excretion is highly variable and may be increased by eating meat. The appearance on urinary amino acid chromatograms of excess taurine is not an uncommon finding in association with general aminoaciduria of the renal type. A specific overexcretion of taurine associated with general aminoaciduria has been reported in pernicious anaemia and in subacute combined degeneration of the cord (Neill and Weaver, 1958). Parish and his associates were unable to identify the type of aminoaciduria but concluded that the abnormal substance had the characteristics of an $\alpha$-amino acid.

In the present study there were 17 affected people: 7 males and 10 females in 4 unrelated families. The pedigrees are consistent with dominant autosomal inheritance which agrees with previous published families with camptodactyly (Murphy, 1926; Spear, 1946; Zumoff, I954). In the study by Parish and his associates, only females were affected, and the authors concluded that the condition was inherited in a 'Mendelian sex-linked' manner, but since 7 sons of the Io affected females were normal this is most improbable. Todd (1929) also described a family in which females only were affected, but again there were 6 sons of the affected females who were normal. Autosomal dominant sex-limited inheritance in these two families is a more likely explanation. In our families there is a suggestion of partial sex limitation but the excess of females is not significant. Male-to-male transmission in family 2 (I.3 to II.8) and family 4 (II.2 to III.2) is incompatible with X-linked inheritance.

Not enough people in the 4 families have been investigated to conclude confidently that the flexion contracture of the fingers and the excessive excretion of taurine in the urine are not inherited independently. One normal person had an abnormal excretion of taurine and one affected one had a normal urinary chromatogram. The families, however, in the present series together with that of Parish and his associates leave little doubt that the association between camptodactyly and abnormal excretion of taurine is real.

\section{Summary}

A contracture deformity of the hands (camptodactyly) characterized by a permanent flexion of the fingers at the proximal interphalangeal joints was observed in 17 people ( 10 females and 7 males) in four unrelated families. The hand abnormality was associated with a specific overexcretion of taurine in the urine. Only one affected person had a normal urinary amino acid chromatogram. The condition was inherited as an autosomal dominant characteristic.

We wish to thank Dr D. C. Cusworth of University College Hospital Medical Unit for the amino acid clearance studies, Mrs P. Balmer for the photography and $\mathrm{Dr}$ C. O. Carter of the Medical Research Councif Clinical Genetics Research Unit for advice on the genetics.

\section{RRFERENCES}

Adams, W. (I891). On congenital contraction of the fingers and its association with 'hammer toe'; its pathology and treatment Lancet, 2, 111 and 165.

Ashley, L. M. (1947). The inheritance of streblomicrodactyly? 7. Hered., 38, 93.

Currarino, G., and Waldman, I. (1964). Camptodactyly. Amer. 70 Roentgenol., 92, 1312.

Datta, S. P., Dent, C. E., and Harris, H. (1950). An apparatus for the simultaneous production of many two-dimensional pape $\bar{B}$ chromatograms. Science, 112, 621 .

Dutta, P. (1965). The inheritance of radially curved little finger Acta genet. (Basel), r5, 70.

Gates, R. R. (1946). Human Genetics. Macmillan, New York.

Hefner, R. A. (1924). Inherited abnormalities of the fingers III subterminal articulation in the proximal joints of the little finger. $\boldsymbol{f}$. Hered., I5, 481 .

(1929). Inheritance of crooked little fingers (streblomicro옹 dactyly). ibid., 20, 395.

- (I94I). Crooked little fingers: (minor streblomicrodactyly) ibid., 32, 37.

Landouzy, L. (I906). Camptodactylie: stigmate organique précoc du neuro-arthritisme. Presse méd., 14, 251.

Moore, W. G., and Messina, P. (1936). Camptodactylism and its variable expression. $\mathcal{F}$. Hered., $27,27$.

Murphy, D. P. (1926). Familial finger contracture and associatee familial knee joint subluxation. F. Amer. med. Ass., 86, 395.

Neill, D. W., and Weaver, J. A. (1958). Amino-acid and proteip metabolism in pernicious anaemia. Brit. F. Haemat., 4, 447.

Neuhof, H., and Oppenheimer, E. D. (I9I4). Congenital contractures of the fingers, with the report of a case of the familial type? Surg. Gynec. Obstet., 19, 193

Oldfield, M. C. (1956). Campylodactyly: flexor contracture of the fingers in young girls. Brit. F. plast. Surg., 8, 312.

Parish, J. G., Horn, D. B., and Thompson, M. (1963). Familiă streblodactyly with amino-aciduria. Brit. med. F., $2,1247$.

Ritterskamp, P. (1936). Eine Familie Mit Kamptodaktylie. Münch med. Wschr., 83, 724.

Schmidt, L. Von (192I). Die Streckung krummer Finger. Dtsch med. Wschr., 47, 564 .

Sinclair, R. J. G., Kitchin, A. H., and Turner, R. W. D. (1960 The Marfan syndrome. Quart. F. Med., 29, 19.

Spear, G. S. (1946). The inheritance of flexed fingers. F. Hered 37, 189 .

Stoddard, S. E. (1939). Nomenclature of hereditary crooked fingers; Streblomicrodactyly and camptodactyly-are the synonyms? ibid., 30, $51 \mathrm{I}$.

Todd, A. H. (1929). A case of hereditary contracture of the litti60 fingers (kamptodactyly). Lancet, $2,1088$.

Zumoff, B. (1954). Congenital symmetrical finger contractures F. Amer. med. Ass., 155, 437. 